Portland State University

PDXScholar

1978

\title{
Outcome evaluation of medical care utilizing Goal attainment scaling
}

Bonnie G. Little

Portland State University

Follow this and additional works at: https://pdxscholar.library.pdx.edu/open_access_etds

Part of the Medical Sciences Commons, and the Social Work Commons Let us know how access to this document benefits you.

\section{Recommended Citation}

Little, Bonnie G., "Outcome evaluation of medical care utilizing Goal attainment scaling" (1978). Dissertations and Theses. Paper 2806.

https://doi.org/10.15760/etd.2801

This Thesis is brought to you for free and open access. It has been accepted for inclusion in Dissertations and Theses by an authorized administrator of PDXScholar. Please contact us if we can make this document more accessible: pdxscholar@pdx.edu. 
OUTCOME EVALUATION OF MEDICAL CARE UTILIZING GOAL ATTAINMENT SCALING

by

BONNIE G. LITTLE

A practicum submitted in partial fulfillment of the requirements for the degree of

MASTER OF SOCIAL WORK

Portland State University

1978 
TO THE OFFICE OF GRADUATE STUDIES AND RESEARCH:

The Committee approves the practicum of Bonnie G. Little presented June 1, 1978.

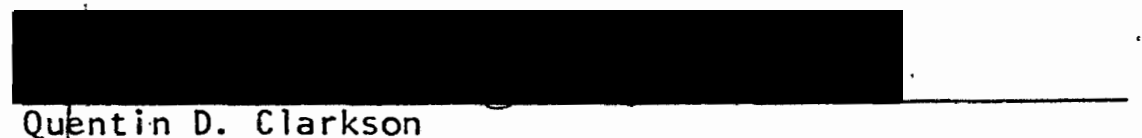




\section{ACKNOWLEDGMENTS}

I would like to recognize the efforts and assistance of those who were invaluable in the creation and presentation of this study. Dr. Quentin Clarkson first introduced me to this subject and was supportive throughout its development. Dr. David Smith and Dr. Joe McCarthy were both helpful in allowing me to use the Family Practice Clinic of the University of Oregon Health Science Center as the base for the retrospective study and provided much assistance and information in regards to medical care and its objectives. Lastly, I would like to acknowiedge the support of my closest friend, Tim Tuttle, who never wavered in his support through all my frustrations and panic. 
TABLE OF CONTENTS

PAGE

ACKNOWLEDGMENTS

iii

LIST OF FIGURES

$v i$

\section{CHAPTER}

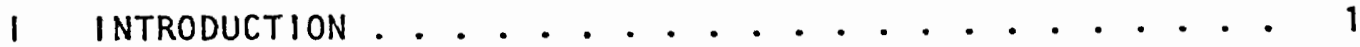

II A REVIEW OF GOAL ATTAINMENT SCALING ........ 3

111 A REVIEW OF THE LITERATURE . . . . . . . . . . 8

Conclusions .............. . 16

IV PROCEDURE OF STUDY ................ 17

$\checkmark$ GAS MODEL FOR THE MEDICAL CARE SETTING . . . . . . 22

Identification \& Definition of Area of Practice . . 23

Identification of the Goals of Treatment . . . 23

Definition of Goals of Treatment . . . . . 23

Follow-up Guide and Utilization Procedure . . . . 26

Intervention with Patient . . . . . . . 29

Writing Criteria to Define Levels of Outcome . . 31

Scoring of the Scales........... 32

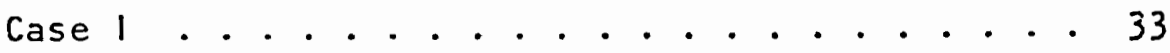

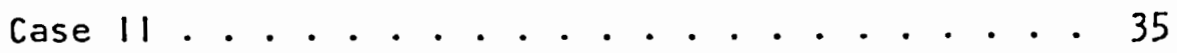

Case 111 .................... 37

Conclusion ............... 39

VI CONCLUSIONS AND RECOMMENDATIONS ......... 40 
CHAPTER

PAGE

A SELECTED BIBLIOGRPAHY . . . . . . . . . . . . . . . . . . . . . 42 APPENIDX . . . . . . . . . . . . . . . . . . . . . . . . . 46 


\section{LIST OF FIGURES}

FIGURE

PAGE

1. Identification of structural, process and outcome goals . . . . . . . . . . . . . . . 24

2. Goal Attainment Follow-up Guide . . . . . . . . . . . 27

3. Case I Goal Attainment Follow-up Guide . . . . . . . . . 34

4. Case 11 Goal Attainment Follow-up Guide . . . . . . . . 36

5. Case $\| 11$ Goal Attainment Follow-up Guide . . . . . . . 38 


\section{CHAPTER 1}

\section{INTRODUCTION}

The purpose for this study was to develop guidelines for the implementation of Goal Attainment Scaling (a mental health measurement technique) in the medical care setting. As a graduate student of social work, I have become involved in the delivery of medical care and am interested in the dynamics of psycho-social variables as they affect the structure, delivery, and outcome of medical services.

The problem inherent in the outcome evaluation of medical care has been the inability to identify, measure, and control for those non-medical factors affecting treatment. Yet, outcome measures are being promoted to evaluate health services at the national ievel for the development of quality assurance programs, usually in the form of Professional Standards Review Organizations (Kessner, 1978, p. 382). Health care providers, however, are concerned, for as of yet, no effective methodology has been found to measure or assure quality (lbid.)

The development of Goal Attainment Scaling was a result of the lack of a measurement tool for mental health providers to utilize when attempting to measure the progress of their clients and to compare the relative effectiveness of various treatment modalities. The unique background environment and probiems of each client could not be reliably controlled; thus, a technique was developed, whereby, individual goals were set for each client and the attainment 
of those goals were measured. Medical care providers are faced with a similar set of circumstances.

So as to become directly involved in the process of evaluation, a retrospective study of prenatal care was conducted at the Family Practice Clinic of the University of Oregon Health Science Center. The procedure of the study and the subsequent guidelines developed form the main focus of the report. To aid in understanding, a review of Goal Attainment Scaling is provided in Chapter 11 ; a literature review of medical evaluation follows in Chapter 111 . The report ends with a discussion of the conclusions and recommendations. 


\section{CHAPTER $1 \mid$}

\section{A REVIEW OF GOAL ATTAINMENT SCALING}

Goal Attainment Scaling (GAS) was first developed in the mid-1960's by Thomas Kiresuk and Robert Sherman at the Hennepin County Mental Center in Minneapolis, Minnesota. This measurement technique was developed with the intention of comparing mental health treatment modalities, and also to serve as a standard evaluation tool applicable within a variety of mental health settings (Kiresuk and Sherman, 1968).

Further the instrument sought to provide cilent speciuc goals which were more closely related to the therapeutic activities of the program than statements of general program goals. GAS was developed then, as a method of goal definition and goal measurement that could be used to evaluate both the extent to which individual goals had been attained and the reflective effectiveness of the treatment used to attain them. (Clarkson, Koroloff, Neuberger, and Hines, 1976, p. 6)

Those first working with GAS developed an experimental design with the intent of evaluating the relative effectiveness of various treatment modalities. This design included the following three steps: "selection and scaling of goals, random assignment of patients to one of several treatment methods, (and) a follow-up of each patient in regards to the scales established at intake" (Ibid.). Within the model developed for use in the medical setting, only the first and last steps will apply. Concern over the evaluation of the benefits of one treatment method over another is not of primary importance in this model, however, that too may be incorporated if desired. The 
focus will center on the evaluation of the extent to which individual patient goals are met, and a reflection over the effectiveness of that treatment and those specific goals.

GAS is based upon a system of scaling which provides for the definition of goals of treatment; (program goals or individual patient goals may be written into scales). Each goal becomes the focus of a separate scale. Each scale is then defined by a set of observable specific criteria: from "worst anticipated outcome" to the "best anticipated outcome." When this technique was first used each scale contained five levels or points on the scale: $-2,-1,0,+1,+2$. Zero is the point of "expected outcome." The patient is rated for each of the scales at a specific level: at the time of intake and again at a pre-determined follow-up time. The changes in scale level noted at the time of follow-up show the attainment for that scale (goal)

The process of goal definition and scale creation is a result of the interaction between the primary care giver (the rater) and the patient. Thus, the successful utilization of this technique lies in the degree of communication between the rater and the patient.

Another advantage of specifying goals in behavioral terms is the clarity of communication between staff members in the service and between services, if the client is transferred from one component to another. (Turner, 1973, p. 23)

A second advantage of behavioral objectives is that they help to insure that the full range of the client's needs are attended to. (Houts and Scott, p. 2)

A weakness of the technique lies in the responsibility and flexibility given to the rater. It is this exact flexibility, however, that allows for evaluation when considering individual patients 
with individual concerns. Lebow speaks to this point by way of underlining the importance of the need for multi-trait and multimethod evaluation which would allow for the delineation of each aspect of the quality of care $(1974, p .336)$. Training in assessment of goals and scale construction is also essential for all those involved (Davis, 1973, p. 47). The use of prescribed common scales can also facilitate the reduction of rater bias (Clarkson, Koroloff, Neuberger, and Hines, 1976, p. 9).

We believe that most rating errors are not due to deliberate faking. Moreover, no rating scale is really proof against distortion by a rater who really wants to do so. Better ratings can be obtained, in our opinion, not by trying to trick the rater (as in forced scales) but by helping him rate. (Smith and Kendall, 1963, p. 151)

Common scales for a homogeneous population is a modification of the original GAS method (Clarkson, Koroloff, Neuberger, and Hines, 1976, p. 10). The model developed for use with medical care at tempts to set common scales for all prenatal care patients. It is important to realize, however, that when using a common scale approach there may be those patients for whom individual scales do not apply, and for whom new individual scales must be written. This would not contaminate the evaluation process if the intent was to measure attainment of the scales, not program evaluation.

In review of GAS literature, nothing was to be found concerning direct use of GAS as a tool for evaluating medical care. In one instance, however, GAS was used to evaluate a communication skills training program for residents within a Family Practice residency program (Carlson, 1974). Linn and Linn, in their article Narrowing the Gap between Medical and Mental Health Evaluation, propose the use of 
GAS in medical care evaluation (1975).

The focus of the literature involved the use of GAS in its traditional and adapted forms in a variety of social agencies, mental health and psychiatric programs.

The central problem (within these agencies) $\because$. has been to bridge the gap between the broadly stated goals of intervention and rehabilitation and the particular objectives of the program. (Kịresuk and Sherman, 1968, p. 445)

In terms of medical care how do you relate general and broad goals of increased health and rehabilitation to the particular situation of one patient with their own unique history and set of circumstances.

GAS has attempted to do this by way of, the process of setting goals, translating goals into behavioral or measurable terms, and then translating these behaviors into scales on which data concerning the goals can be obtained. GAS does not, however, imply a particular type of design or data analysis (Clarkson, Koroloff, Neuberger, and Hines, 1976, p. 11). Thus, it is important to keep in mind, when examining the guidelines in Chapter $V$, that changes and adaptations can be made if the basic processes listed above are maintained.

GAS has been used as a case management tool, peer review, in house needs assessment (Kilber and Swanson, 1975; Honigfeld and Klein, 1973; G.O.R.K., 1975) as well as program evaluation.

The evaluation of medical care can be complicated by many intervening variables, those foreseen and those not foreseen (social, psychological, genetic, economic, etc.) that can not be under the direct control of a physician. GAS is preferred whenever measurement on some established instrument is not available or when measurement on any continuous variable is not possible. This is often 
the case with medical care. It is especially suitable when a behavioral measure is desired (Clarkson, Koroloff, Neuberger, and Hines, 1976, p. 12, 13).

If we consider GAS to be a precise and measurable statement (in behavioral terms) of a contract between therapist and client, we can consider use of GAS in evaluation. (Ibid.) 


\section{CHAPTER \|\|}

\section{A REVIEW OF THE LITERATURE}

During the past decade, economic, political and consumer pressures to assess medical care have increased exponentially; there is now a national commitment, not only to quality evaluation, but to the worthy but grandiose objective of quality assurance. This commitment is being made in the face of increasing evidence that feasible and reliable methods to assess medical services -- let alone to assure quality -- have yet to be developed. (Kessner, 1978, 381)

Medical care evaluation has been linked to the quest for quality assurance. Kessner has described the situation of medical care evaluation as one of cognitive dissonance. The more we are committed to assessing care and its quality, the harder we try, even in the face of a lack of effective methodology (lbid., p. 382).

In the quest for quality care the definition of what that means becomes ambiguous. "The relativity of good care becomes a central problem for assessment" (Lebow, 1974, p. 328). Basic questions arise: What is quality? What is being evaluated? Who is responsible? How do we do it? Who defines quality? Donabedian (1966) states that little is known about how physicians define quality. He suggests that our pre-occupation with evaluating quality should be shifted towards understanding medical care processes (lbid., p. 196). One problem with quality measurement stems from the research methods utilized which incorporate value-laden terms such as "more" or "less" (Linn and Linn, 1975, p. 608).

GAS allows for the objectives of treatment to be specified in 
behavioral terms, providing for the measurement of what you want to happen (lbid.). This skirts the issue of defining the standard of quality. Performance measured against objectives allows a built-in system of evaluation which provides for individual feedback ( 1 bid.). The level of performance is the level of quality;, which may be linked not only to physician performance but also to patient performance. Kessner (1978) discusses the need for an evaluation program that is a part of direct practice (Ibid., p. 385).

Quality is often defined narrowly within the realms of the technical management of an illness, ignoring the role of prevention, rehabilitation, coordination and continuity of care, and the patient/ physician relationship (Donabedian, 1966, p. 192). The boundaries of medical care are also defined and limited by the care giver and the evaluator. Psycho-social management of health and $i$ llness have often been exciuded (lbid., p. 181). In search for a definition of prenatal care to utilize within this study, four objectives were found:

(1) The prevention of the occurrence of behavior or disease, likely to result in adverse consequences to the pregnant woman and infant, where this is preventable; (2) The minimization of the consequence of conditions which cannot be prevented, be they pre-existing or those which are identified or develop during pregnancy; (3) The maintenance of the pregnant woman's health by counteracting the adverse affects of the maternity process, be they physiological or psycho-social, and by preventing iatrogenic disease in the fetus; (4) The rehabilitation of women whose pregnancies terminated in a poor outcome, and the upgrading of the conditions of pregnant women or newborns with serious general health or social problems, including those which are pre-existing, newly identified, or developing during the maternity cycle. (Lane and Kellman, 1975, p. 795)

Within the range of these objectives the status of the newborn is but one of the possible outcomes of the care the mother received (lbid., p. 796). 
Another issue that is given much attention, especially within the realm of outcome evaluation, is that of the interplay of intervening variables in the life and care of the patient. All areas of one's life and background impinge upon one's response to medical care: socio-economic, demographic, medical history, genetic background, education, and emotional well-being (Brook and Appel, 1973; Gonnella, Louis, and McCord, 1976; Linn and Linn, 1975). Does outcome evaluation, then, measure medical care?

Most problems of pregnancy outcome are probably multifactorial. The search for causal factors for the nongenetic component usually relates to the mother's external environment. . . It is important to unravel the maternal host factors and to place in perspective the roles of internal and external environment. (Emanuel, 1976, 119)

This complex task impedes the development of evaluating just what are the outcomes of care. GAS does not seek to show causal factors at this time; however, it may be useful in determining what are the results of medical care in a more specific way than relying on mortality, morbidity, and prematurity statistics. Social adjustment, level of physical and psychological symptoms and patient satisfaction should be inlcuded in the measurement of outcomes (Linn and Linn, 1975, p. 609). A more specific knowledge of the outcomes of care could lead to the identification of problem areas and to further research.

The difficulty of prognosis is also related to the above issue of intervening variables. Brook and Appel (1973) discuss the use of esitmates of group outcome as a method in evaluating care. They found this to be the least satisfactory "in terms of physician willingness to provide estimates and validity of estimates" (lbid., p. 1328). This approach requires the physician to judge care as a 
function of its results rather than in terms of what a physician does (Ibid.). GAS in medical care is contingent upon the ability of the health care provider to project what will be the outcomes of care based upon an individual's history and environment. Brook and Appel perceive the ineffectiveness of the estimates of group outcomes as a result of 'medical education and research (lbid.).

Williamson proposes a framework in which diagnostic and therapeutic outcomes are routinely assessed; process activities are studied only if outcomes are not meeting accepted standards (1971, p. 564). The value of this design "requires the providers of care to focus on prognosis" (Ibid., p. 565). In addition to this, the search for multi-determinants of outcome are stimulated, and learning needs are identified (lbid.).

Quality, intervening variables contaminating the task of evaluation, and the difficulty and importance of prognosis have been discussed up to this point. Resistance on the part of the health care team is another factor inhibiting the development of effective evaluation. It is of foremost importance in evaluation for those involved to be agreeable to and participators in the evaluation process. This is especially true when utilizing GAS which requires time, thought, and energy in the development of scales and criteria. Conflict may arise from those not committed to the project which may contaminate the results by lack of compliance with set procedures. "This is understandable as most clinicians are accustomed to functioning in a milieu in which performance is not systematically under review" (Honigfeld and Klein, 3973, p. 22). The ability and authority of anyone but their own peer to judge the care they provide is a challenge (Lane and Kellman, 1975, 
p. 793). Davis discusses this factor in his article regarding goal attainment evaluation and suggests a series of steps the evaluator may take to lessen resistance: empathize with potential feelings of threat; provide confidential and supportive feedback; offer help in planning effective corrective responses to less-than-desired results; build on a baseline of results with improvement reflected in periodic re-evaluations; and provide pre-implementation dry runs, participation, discussion and input (1973, p. 45).

The evaluation of medical care involves research and methodology at three primary levels of service: process, structure, and outcome. "Ultimately the purpose of the evaluation of health care is to facilitate improvement in the delivery and outcome of medical services" (Williamson, 1971, p. 569). The desire for quality assurance has also led to the interest in consumer attitudes and satisfaction. Management, cost efficiency, datà collection methods, techniques of analysis and the development of criteria are also concerns. Within the literature, major conflict exists over what method is considered to be the most valuable in evaluating quality care (Brook and Appel, 1973; Donabedian, 1966; Kessner, 1978; Lebow, 1974; Lorei and Schroeder, 1975; Sanazaro, Goldstein, Roberts, Maglott, and McAllister, 1972; White, 1970; Williamson, 1971).

Those supporting the "process" method of evaluation cite the lack of evidence linking process activities to the actual outcome of care.

Only in a limited number of specific diseases and conditions can the observed end results in patients be attributed directly or indirectly to the medical care that they have received. (Sanazaro, Goldstein, Roberts, Maglott, and McAllister, 1972) 
Thus, measures of outcome would not accurately assess the medical care received. It would be contaminated by a combination of factors: demographic, socio-economic, psychological and genetic. Those supporting the use of "outcome" evaluation state the need for knowing the end results of care (Fessel and Van Brunt, 1972; Williamson, 1971). "What really matters is whether the patient is coping better than he did before he encountered the health care system" (White, 1970, p. 245). Donabedian (1966) critiques the use of outcome over process methods. He does state, however, that outcomes are ultimate validators of the effectiveness and quality of medical care; they are also very difficult to measure (lbid., p. 169).

Lebow (1974) discusses the need for evaluation designs incorporating structure, process, outcome, and what he calls "impact" (the effect of care of the overall community setting). Kessner, Kalk, and Singer (1973) take this one step further. Within their framework utilizing the "tracer" method, evaluation results are fed back into the delivery system which provides the opportunity for them to be acted upon.

Gonnella, Louis, and McCord (1976) have devised a method of assessing the outcome of ambulatory care -- "staging." This method is based upon

defining different levels of severity for specific medical problems . . The seriousness of a patient's condition at some point in the treatment process is a good indicator of the outcome of the previous parts of the process. (lbid,. p. 13, 14) 
A variety of approaches have been used in the assessment of the quality of prenatal care. Emanuel (1976) discusses the general problems involved in evaluation due to the multi-factorial nature of pregnancy outcome. The primary independent variables used in prenatal care studies in relation to outcome are the number of visits, and the time at which prenatal care commenced (Ibid., p. 129). These variables are contingent upon maternal behavior; however, there is no good evidence that they relate to the activities of the physician "which are crucial in evaluating the efficiency of prenatal care" (lbid.).

Much attention has been given to the need for the identification of the high-risk pregnancy (Breifs, February 1976, and May 1976; Ryan, 1975). Ryan states that maternal, fetal, and neonatal mortality may be reduced if maternity patients and newborns are identified as high risk at an early stage in care; and he continues to suggest the need for the development of a regional perinatal care system which would assure the accessibility of needed quality care "within the constraints of economic feasibility" (Ibid., p. 375). A basic problem arises, however, in the defining of what consititutes a highrisk factor (Briefs, February 1976, p. 25). Before studies linking process and outcome are designed in this area of evaluation, an adequate classification of high-risk factors must be available in addition to a "rigorous classification of the regimes of care themselves" (Ibid., p. 26).

Studies relating early prenatal care with birth weight have shown no consistent association between process and outcome. Although, the importance of early prenatal care has been stressed so as to 
allow for the identification of the high-risk patient (Ryan, 1975). Ferster and Jenkins (1976) attempted to show a relationship between the use of consultatnt obstetricians for the delivery of obstetric care and perinatal mortality. Lawson (1974) binds process, patient satisfaction, and structure together and states the need for research into patient's attitudes toward the organization and administration, the confusion of responsibility, shortage of hospital beds, and inadequate antenatal care as essential areas for further inquiry. "Pregnancy should be reviewed as a whole and evaluated in perspective" (Ibid., p. 50). Nunnally and Aguiar (1974) are also concerned with the measurement of attitudes towards prenatal and delivery care -- patient satisfaction.

The most comprehensive model for the evaluation of prenatal medical care was found within the Lane and Kellman (1975) framework. They have developed a model that specifies indicators of the quality of sturctural, process, and outcome variables, linked to medical and consumer criteria. A pre-set list of criteria are identified for each major dimension of prenatal care: accessibility, availability, adequacy, responsiveness, and effectiveness (Ibid., p. 796). This model is similar to that of GAS in that goals and objectives for care are stated, however, in a global way. Checklists are available for describing the process activities. However, a procedure for translating the goals into specific criteria for each individual patient upon a scale for measurement is not available. The purpose of this framework is for the retrieval of information retrospectively, not as a tool to aid in the process of health care provider/patient interaction and communication. It may be valuable for those who would 
use the GAS framework in the future to develop a set of standardized criteria for each of the scales as was attempted by Lane and Kellman.

\section{CONCLUSION}

In review of the literature regarding medical care evaluation many key issues arise: definition of quality care, choice of methodology, difficulty of prognosis and relating care to outcomes, and the resistance on the part of health care providers toward assessment. Studies have primarily utilized chart audits to assess process activities and outcomes of care. Patient satisfaction and perception of care and physician/patient communication have relied on consumer questionnaires for their data. Nowhere was 1 able to find a study built upon the direct setting of goals with individual patients and subsequent assessment of the attainment of those goals. Kessner (1978), however, is pessimistic that effective evaluation will result if major changes are not taken within the structure of medical care itself. He calls for practicality in implementation, and the need for programs that will influence the health care system and/or the well-being of patients (lbid., p. 381). 
CHAPTER IV

\section{PROCEDURE OF STUDY}

Prenatal care was chosen as the focus of the implementation of Goal Attainment Scaling.(GAS) in the medical care setting. This area of medical care was chosen for several reasons: the outcome is tangible -- the delivery of an infant; a specific time frame is involved -- gestation; specific goals and process activities are available with which to monitor and create scales; and the availability of a clinic for gathering data.

As a basis for this report, a retrospective study was conducted at the Family Practice Clinic of the University of Oregon Health Science Center, Portland, Oregon. Dr. David Smith (who was at that time the director of the clinic) was supportive of the idea of investigating the utility of measuring prenatal care outcomes with GAS, and thus made available for chart review the prenatal population of the Family Practice Clinic.

The main objective for the collection of the data was to determine what data can be obtained from the patient's chart regarding prenatal care, and also to discern how this information is used for the treatment and care of the patient. GAS is based upon the assumption that goals of treatment can be defined, and the criteria defining the objectives must be specified. It was my desire, at the outset, to determine from the chart the goals the physician and patient are working toward, and the specific criteria defining the outcomes. A 
data sheet was compiled, upon which was a check list of variables concerning the patient's health, medical status, labor and delivery, and psycho-social situation. (A copy of the data sheet can be found in the Appendix).

The population under review was drawn from those women who had receieved prenatal care at the Family Practice $\mathrm{Clinic}$, and who gave birth at the University of Oregon Health Science Center in 1976. Thirteen (26\%) of the women were single; nineteen (38\%) were twenty years of age and younger; twenty-three (46\%) of the women were primiparous. For each woman involved there were three charts to review: the patient's clinic chart, hospital chart, and the newborn infant's hospital chart. The charts reviewed were not chosen in a random fashion. The medical secretary sent for those charts available from medical records. A small sample was chosen with the purpose of discovering what information is available within the charting system regarding prenatal care; therefore, a representative sample was not necessary.

Following the chart review, an attempt was made to extract those processes and goals that are necessary for prenatal care as presented by the chart system. This proved to be an impossible task. My most outstanding observation was the lack of data recorded, and the time and energy involved in trying to locate a specific piece of information. This problem has been addressed throughout much of the current literature relating to medical care evaluation. Donabedian discusses this issue and states that the recording of data is itself a legitimate dimension of the quality of care (1966, p. 189). Other aspects of record keeping are addressed, in addition to the incompleteness of 
records. Charts have been found to be illegible, innacurate, and biased by the subjectivity on the part of the examiner (Fessel and Van Brunt, 1972, p. 134; Lane and Kellman, 1975, p. 793; Lebow, 1974, p. 328). "Yet past attempts to measure the quality of care, (however), have relied heavily upon the examination of the recorded process of medical care" (Lane and Kellman, 1975, p. 793).

A thorough reading of each of the three charts per patient was necessary to extract the information sought. Records were incomplete and contradictory. Pelvic measurements were of ten called adequate when in actuality the measurements calculated were inadequate. Some charts contained no pelvic measurements. In 32 cases (64\%) no PPD was recorded; in 26 cases $(52 \%)$ there was no record of immunizations; 7 cases (14\%) had no record of a Pap smear. Within the chart system, there was no way of determining whether the unborn child was in fact wanted. No information was to be found concerning preparation and care for the mother and child in the future: are there suitable living arrangements, housing, finances, emotional support, knowledge of child care, diet and nutrition? Kessner, Kalk, and Singer in a discussion of the tracer method of evaluation state "that good medical records are a requisite for good medical practice" (1973, p. 193).

In ten cases, some notes were recorded regarding the social situation of the patient, either by physician or social worker. For the most part, these women had marital, family, financial and housing problems. How this information was used and followed up on is not clear. These women may have had the tests and measurements referred to above; they may have had support systems at their 
disposal, and the knowledge necessary for a smooth pregnancy, delivery, and care of a newborn infant; however, this information could not be found by reading their charts.

In summary, the major concerns and goals of the women who were experiencing pregnancy, or the expectations and goals of the physician attending them could not be discerned. The desired results of treatment and care is not evident through the existing chart system, whether process activities are complete or not complete, recorded or not recorded. Did the patient receive the care she wanted and/or needed? Does the chart system allow for the identification of procedures and methods that provide for effective treatment of patients? What is adequate prenatal care? Within current health record data little salient consumer-related information is reflected: expectations, concerns, and satisfactions (Lane and Kellman, 1975, p. 794).

The answers to the above questions can be addressed by incorporating the following three tasks into the medical care chart system: develop a clear statement of goals; identify measurable objectives consistent with goals; define acceptable standards of performance. GAS was built around these three tasks and within its boundaries lies the flexibility needed for outcome evaution of medical care (Linn and Linn, 1975, p. 611).

An attempt was made to selectively apply GAS to several of the charts reviewed; however, this was unsuccessful due to the problems mentioned earlier: the inability to define desired outcomes, (and thus to determine what scales are required); and the incomplete recording which hampers the measurement of possible scales. At this point, a retrospective evaluation incorporating GAS measurement 
techniques was deferred. The focus of the evaluation research turned toward developing guidelines for the implementation of Goal Attainment Scaling in outcome evaluation of medical care. 


\section{CHAPTER V}

\section{GAS MODEL FOR THE MEDICAL CARE SETTING}

After much thought, frustration and attempts at trying to explain the value of GAS in the medical care setting to physicians and other medical care personnel I came into contact with, I realized that the key was to develop a specific technique in communicating the basic concepts and applicability of Goal Attainment Scaling. (Dr. Stuart Levy, a resident within the Family Practice Clinic at the University of Oregon Health Science Center from 1974-77, had previously attempted to utilize GAS in his practice of medicine and had encountered similar frustrations).

A descriptive case method was chosen to demonstrate the implementation of GAS with obstetric patients. As a model for outcome evaluation three cases will be presented taken from the population of the pilot study: Names and identifying criteria have been changed so as to secure anonymity. Each of the cases will represent a differing population group: Case 1 . Patients requiring medical intervention during pregnancy; Case 2. Patients requiring educational intervention during pregnancy; Case 3. The no problem pregnancy. These categories are based upon the guidelines presented by the Commission on Perinatal Health (Ryan, 1975). Three levels of obstetric care are identified:

the uncomplicated term pregnancy that produces a mature healthy newborn . . . the complicated cases where resources 
must be available for a wide variety of problems... and the exceedingly complex case or for the seriously ill newborn (which) may demand special personnel or facilities or services which are not required by any other patients. (lbid., p. 376)

Before the case presentations, the tasks necessary for the setting up of the evaluation procedure will be outlined.

\section{Identification And Definition of The Area of Practice}

The focus of this study was identified as being prenatal care of those women being seen at the Family Practice Clinic and having delivered in 1976 at the University Hospital.

Identification of The Goals of Treatment

The purpose of the pilot study was an attempt to identify the concerns of patient and physician by way of a chart review. The drawbacks and failings of this approach were addressed earlier. With the input and cooperation of Drs. David Smith and Joe McCarthy, I was able to identify eleven factors having import in the course of pregnancy. When designing a similar program, it would be important for all participating members of staff to be a part of the identification process. As a part of the identification of goals, a look at process and structural variables was important in developing a global focus of the program (Donabedian, 1966, p. 206). A chart identifying these can be seen on the following page. (See Figure 1.).

\section{Definition of Goals of Treatment}

Definition becomes a necessity when goals are operationalized into scales for measurement. All staff members utilizing this method must be consistent within their own measurement of scales. Following 
STRUC TURE

Financial support

Housing

Transportation

Educational needs

-- prenatal info

-- public school

-- nutrition

Support systems

-- mate

-- family

-- friends

- social agency

-- church
PROCESS

OUTCOME

Seen early in pregnancy Delivery near term

Initial history $\&$ physical Appropriate weight $\&$

Clinical pelvimetry

length for gestation

Routine laboratory work

- Good APGARs

Initial blood type \&

Lack of prenatal

complications

- maternal

-- neonatal

VDRL, CBC @ 36 weeks

Regular vitamins \& iron

Maternal weight

appropriate

Adequate diet

Psycho-social

Appropriate weight gain/loss

situation stable

Avoidance of drugs/meds,

alcohol, cigarettes

Early detection of

-- infections

-- deceleration

-- anemia

- eclempsia

-- hema pre-mature rupture

Psycho-social assessment

-- emotional support

-- finances

-- housing

-- prenatal information

Good dates

-- clinical E neonatal assessment

Figure 1. Identification of structural, process, and outcome goals. 
is a list and description of the eleven scales chosen to measure outcomes of prenatal care.

Term delivery. A specific time frame defining the expected time of delivery.

Birth weight. A specific weight range expected in correlation with the time expected at delivery.

APGAR score. "The evaluation of a newborn infant's physical status by assigning numerical values to heart rate, respiratory effort, muscle tone, reflex irritability, and skin color" (Stedman's Medical Dictionary, 1972, p. 1129).

Prenatal complications, neonatal. Those medical problems occurring with the fetus affecting fetal and/or maternal health, or similar complications with previous pregnancies.

Prenatal complications, maternal. Those medical problems occurring with the woman düring pregnancy affecting maternal and/or fetal health, or pre-existing medical status of the woman affecting maternal and/or fetal health.

Attitude toward pregnancy. Assessment regarding patient's and/or families attitude of acceptance or rejection of pregnancy.

Prenatal inforamtion. Assessment of the need for prenatal classes; previous attendance with other pregnancy; measurement of the number of classes attended.

Maternal weight. Weight gain and/or loss desired for a specific individual.

Living situation. Desired change or maintenance of a specific living situation: where living and with whom?

Financial arrangements. Financial support available to support 
mother and newborn, and/or her family in regards to food, housing, transportation.

Emotional support. A measure of the number of significant others in the life of the individual who are available to meet the needs of the individual.

\section{Follow-up Guide And Utilization Procedure}

Once the scales have been operationalized, decisions must be made regarding the design of the evaluation instrument. I have chosen to follow a design utilizing a 5 point scale of +2 to -2 . Variations have been used: +1 to +5 and +1 to -1 . An example of the Follow-up Guide designed for the outcome evaluation of prenatal care can be found on the following page. (See Figure 2.).

A weight of priority may be assigned to the individual scales. For the purpose of this study, I did not think it necessary to weight the scales.

After the design of the guide has been made, questions arise regarding the utilization procedure. Who will use it? When is it to be used? When and who defines the specific criterion used for the measurement of the scales? Who has the responsibility for the charting? When are the measurements tallied? Where is the guide to be filed?

Physician and social worker have the primary responsibility for utilization and charting, i. e. defining specific criteria for the measurement of the scales for each individual patient, and the assessment of where that patient is on the scale at a certain time period. Six of the scales, term delivery, birth weight, APGAR score, 


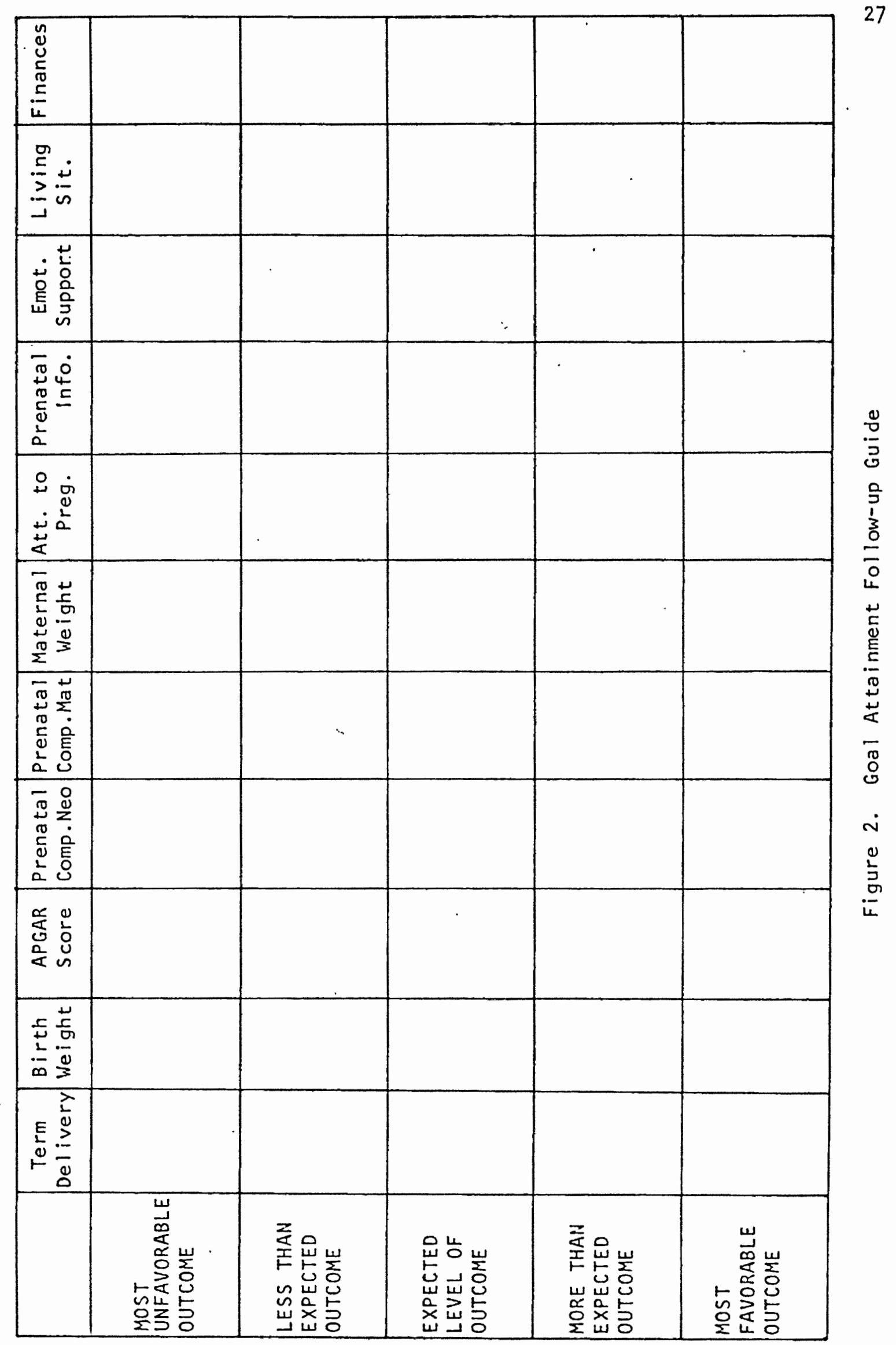


neonatal prenatal complications, maternal prenatal complications, and maternal weight are medical variables, therefore, the responsibility of the physician. The remaining five scales, attitude toward pregnancy, living situation, emotional support, finances, and prenatal information fall into the psycho-social category and are the responsibility of the social worker. The prenatal information scale was assigned to the social worker for this area includes more than medical information and the social worker may be able to provide more individual time with the patient than could the physician.

When is the guide to be used? After the initial history and physical of every obstetric patient, it would be the physician's responsibility to assess what are the criteria describing where the patient will be at the time of delivery, for each of the six scales. These criteria would describe the expectations of the physician for a particular patient. Possibly the physician and patient together would define the criteria as in the case of maternal weight where a specific goal may be set. The importance for communicating this information to the patient cannot be stressed enough. It is my belief that this could aid in increased patient understanding and compliance with medical procedures. Linn and Linn speak to this issue and state that "patient compliance is probably related to the degree of satisfaction with care and their perception of the doctor/patient relationship" $(1975$, p. 612). Lebow also focuses on the importance of patient perception of care received (1974, p. 336). Accuracy of perception, in turn, is based upon communication.

Upon referral, the social worker would follow with an assessment of the patient's psycho-social situation and would with the patient 
define the expectations for each of the five scales at time of delivery. The measurements would then be tallied at first postnatal follow-up appointment, and a score assigned. The guide would be filed in the patient's regular clinic chart with the prenatal information sheet, after the first prenatal visit. For individual physician/social worker feedback, they may want to individually develop a record keeping system so as to evaluate the overall outcomes of all of their own patients in a given time frame. Outcome evaluation for a total clinic may be analyzed if all outcome scores are stored within the clinic's computer center, if available.

\section{Intervention With The Patient}

Essential to the success of this measurement technique is the ability on the part of the physician to gather all pertinent data relating to the scales and the recording of the information in the chart. The author realizes the pace at which physicians must sometimes function, and because of this it may not always be possible to write criteria for a follow-up guide on each patient during a certain day; however, a well charted history and physical may assist the physician at a later date in defining their expectations for a particular patient. This also holds for the social worker.

The role of the social worker has not always been well defined within the medical setting and because of this the use of this practitioner has often been inappropriate or she/he has not been used at all. To aid in understanding, I will define medical social worker. The medical social worker aids the health team in understanding the psycho-social, economic, emotional, and cultural factors 
in relation to the patient's medical condition, diagnosis, prognosis, treatment, and recovery. This information is used in working with the patient and family to provide support in times of stress, and to encourage optimal utilization of medical care. In addition, the social worker acts as liaison between the medical care system and community resources.

Patients often feel intimidated or fearful of physicians and because of this hide attitudes or social circumstances that could have a bearing upon their ability to care for and raise a child. of ten these are the people who are in need of special attention and/or care, and who often drop out of the services provided. The following is a list of reasons explaining why people (especially those of a lower income) drop out:

The lack of understanding of the worth and value of the services; the reception that they received at the hospital and the amount of waiting time required; the lack of appropriate clothing; the lack of baby-sitting services; and the lack of money for transportation. (Briefs, February 1969, p. 21)

The information above underlines the importance of clear communication with the patient and the need for possible social work intervention. The following is a partial list of factors indicating social work referral: teenage pregnancy, unwed mother, developmentally delayed patient, depression, ambivalence toward pregnancy, marital and/or family problems, financial, housing, or transportation problems.

A hospital or clinic may want to devise its own check list to aid in the identification of high-risk pregnancy: medically, socio-economically, or psychologically. The importance of this 
process, however, does not take the place of measuring outcomes. GAS could aid in the evaluation of high-risk pregnancy management.

\section{Writing Criteria To Define Levels of Outcome}

Specific criteria are observable behaviors, medical test results, dates, events, etc. that show when the outcome has been attained. It is important that the indicators can be easily judged so as to allow someone who has had no contact with the clinical or therapeutic procedures to score the goal attainment (Kiresuk and Sherman, 1968, p. 447). Each scale has five levels for which observable outcomes are defined, ranging from "most favorable outcome" to "most unfavorable outcome." Point 0 is the expected level of success for each scale. It is necessary that this point and at least two other levels be defined. Definition of all five levels is hoped for.

Much time is often consumed within the process of translating goals into specific criteria for measurement. One is often forced to set arbitrary criterion as the standard for measurement due to the lack of an empirical base. This is often true for those using GAS for GAS is designed to allow for measurement in those circumstances where previous standards have not been set. Such is the case with many areas of medical care where specific treatment is contaminated by the intervening variables of individual patient background and environment (Brook and Appel, 1973; Donabedian, 1966; Emanuel, 1976; Gonnella, Louis, and McCord, 1976; Lebow, 1974; Linn. and Linn, 1975). "Arbitrary criterion are intuitive and are established using past experience or hunches" (Clarkson, Neuberger, and Koroloff, 1976, p.5). The challenge of the rater then moves to the ability to go from 
an arbitrary to a more data-based standard (Ibid. ).

Scoring of The Scales

The weights and raw scores on the Follow-up Guide are the only munbers used in calculation of the Goal Attainment Score. The value of GAS, however, need not be confined by the use of the Goal Attainment Score which is for statistical purposes. The technique of Goal Attainment Scaling may be used as a process in itself to aid in structuring the provision of adequate medical care and intervention by the health team. 
CASE I

The case history below is one representation of the obstetric patient requiring close medical supervision during pregnancy.

Mrs. A. is a 25 year. old married woman. Last menstrual period was 6 weeks ago. She is Gravid two, Para one, no abortions. She was seen last week. Chief complaints were tiredness nausea and headaches. She has had a positive urine screen for pregnancy. Two years ago she was admitted for toxemia of pregnancy; her first child was delivered at 34 weeks by Ceasarean section, stillborn. No reported allergies; she has had measles, chicken pox, and mumps. Has had a recent PPD, all immunizations, and Pap smear. Pelvis is clinically adequate. Initial weight: 145 lbs. Height: 5 feet, 2 inches Blood Pressure: 140/60 HCT: 35.0 Toxoplasmosis titer: $\leqslant 1 / 16$ HIA titer: $\leqslant 1 / 16$ Urine albumin: no trace Sugar: Yes Mrs. A. describes herself as being happily married. Both her and her husband want a child and desire prenatal classes.

The problems identified above include a history of prenatal complications involving both mother and neonate, obesity, and elevated sugar. No psycho-social problems are evident. From this history, criteria have been defined for the measurement of the scales; they appear in Figure 3. The criteria defined for the medical scales are examples of specific criteria; they are not meant to be evaluated on the correctness of prognosis. This holds for each of the three cases. 


\begin{tabular}{|c|c|c|c|c|c|}
\hline 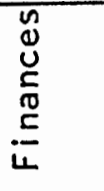 & 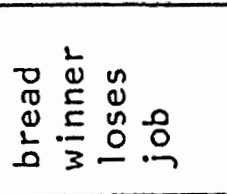 & & 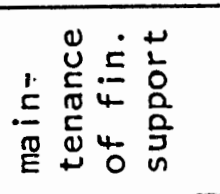 & & \\
\hline 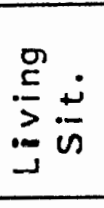 & 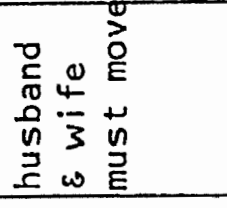 & & 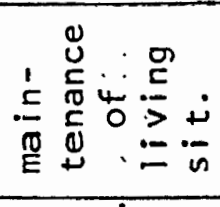 & . & . \\
\hline 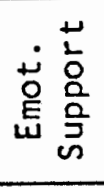 & 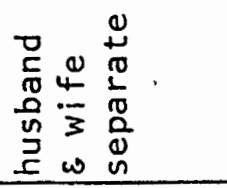 & & 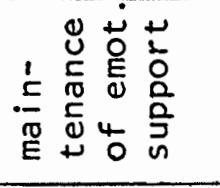 & - & \\
\hline 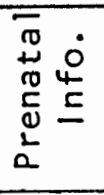 & 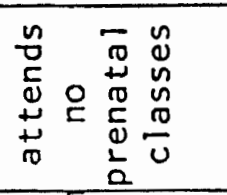 & & 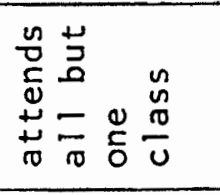 & & 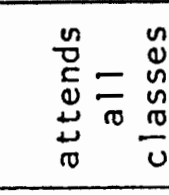 \\
\hline 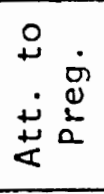 & 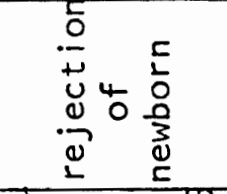 & . & 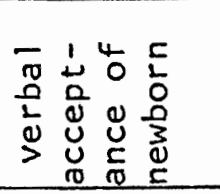 & & \\
\hline 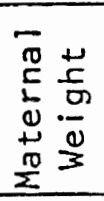 & 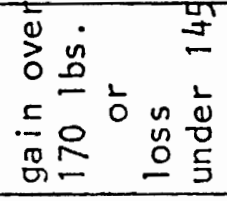 & & 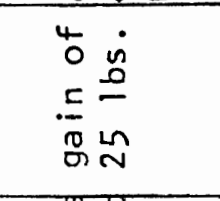 & & 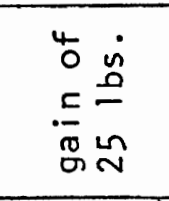 \\
\hline 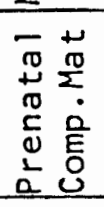 & 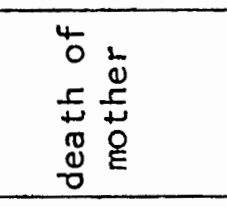 & . & 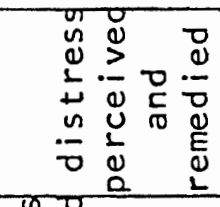 & & 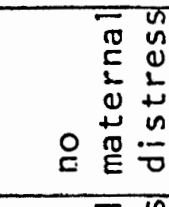 \\
\hline $\begin{array}{ll}\pi & 0 \\
\pi & 0 \\
+1 & z \\
0 & 0 \\
\frac{L}{0} & 0 \\
1 & 0 \\
1 & 0 \\
2 & 0\end{array}$ & $\begin{array}{ll}4 & 5 \\
0 & 2 \\
5 & 0 \\
+1 & 3 \\
0 & 0 \\
0 & 5 \\
0\end{array}$ & & 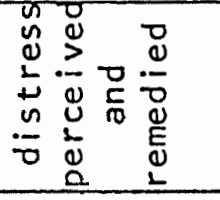 & & 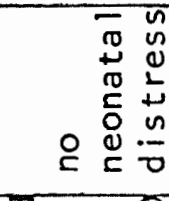 \\
\hline 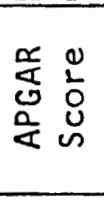 & 0 & & 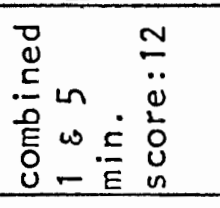 & & 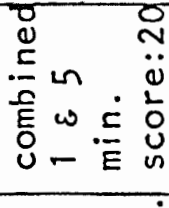 \\
\hline 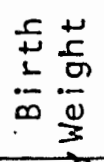 & $\stackrel{0}{\dot{m}} \underset{v}{ }=$ & & $\begin{array}{l}\text { in } \\
\text { n } 0 \\
\text { in }\end{array}$ & & $\hat{\Lambda}: \dot{0}$ \\
\hline \multirow[t]{2}{*}{$\frac{E}{\frac{1}{0}} \stackrel{\frac{1}{2}}{\frac{1}{0}}$} & $\therefore$ 울 $\frac{n}{0}$ & & 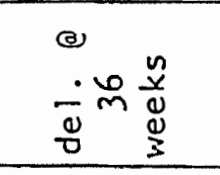 & & 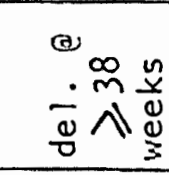 \\
\hline & 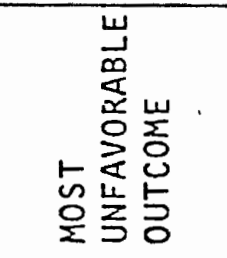 & 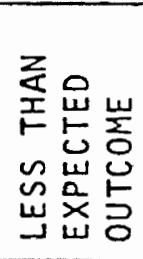 & 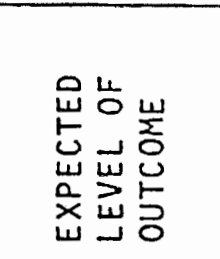 & 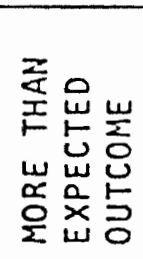 & 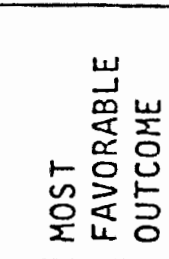 \\
\hline
\end{tabular}




\section{CASE $\|$}

The case history below is one example of an obstetric patient requiring educational and environmental intervention.

Ms. G. is an unmarried woman, age 15. Last menstrual period was 10 weeks ago. She is Gravida one, Para 0. First menstrual period age 12. She was seen last week complaining of nausea, vomitting, tiredness, and headaches. She has had a positive urine screen for pregnancy. She has had a recent PPD, however, has no recollection of having had any immunizations, and no Pap smear. No known allergies. Has had no childhood diseases. Pelvis is clinically inadequate.

Initial weight: 110 lbs. Height: 5 feet, 3 inches Blood Pressure: 110/76 HCT: 30.0 Toxoplasmosis titer: $\leqslant 1 / 64$ HIA titer: $\leqslant 1 / 16$ Urine albumin: no trace Sugar: none Was seen by social work. Low socio-economic status and family problems. She was kicked out of the house 2 weeks ago, and is living with a girlfriend temporarily. No money. Boyfriend is not around. Poor hygiene and diet. Smokes 2 packs of cigarettes a day. Dropped out of school. Ambivalent about pregnancy.

The problems identified above primarily constitute socioeconomic and environmental problems. The criteria defining the levels of outcome are presented in Figure 4. The "expected levels of outcome" for the medical scales are within the normal range. (Due to inadequate pelvis, she may require a Ceasarean section. This, however, is viewed as a process activity, not a measure of outcome, and so is not included on the Follow-up Guide).

Social work intervention is definately indicated. The "expected level of outcome" is defined for those scales taking into consideration her past family history of social interaction, her motivation, her opportunity to take advantage of community resources, and her capacity to do so. 


\begin{tabular}{|c|c|c|c|c|c|}
\hline 吕 & 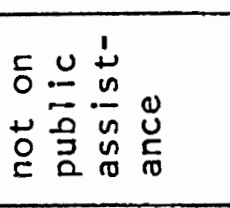 & & 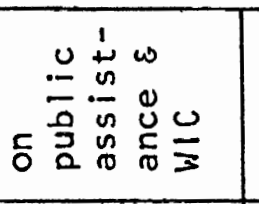 & & 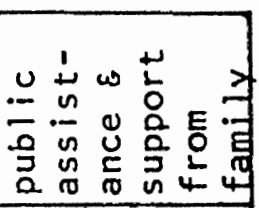 \\
\hline$\frac{\infty}{2}$ & 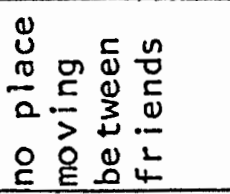 & & 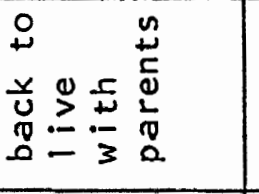 & & 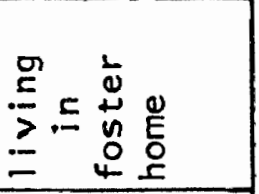 \\
\hline 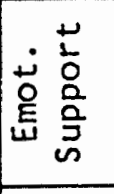 & 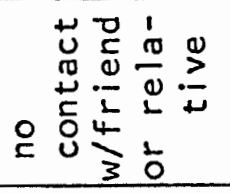 & & 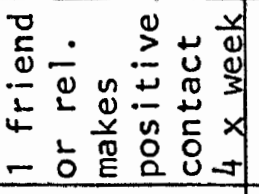 & & 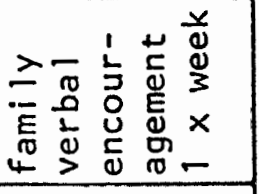 \\
\hline 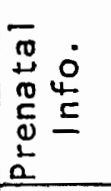 & 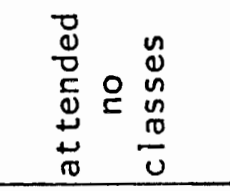 & . & 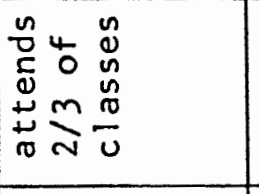 & & 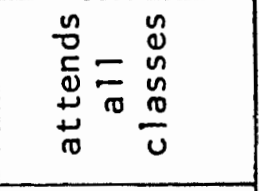 \\
\hline $\begin{array}{l}\dot{0} \\
\dot{0} \\
\dot{0} \\
\dot{0}\end{array}$ & 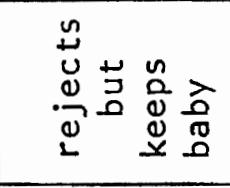 & . & 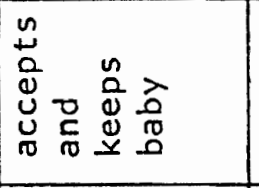 & & 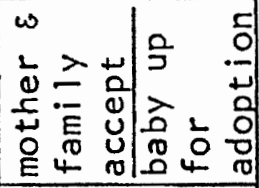 \\
\hline 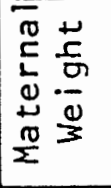 & 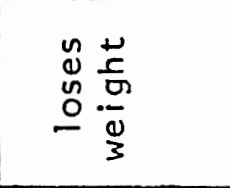 & & 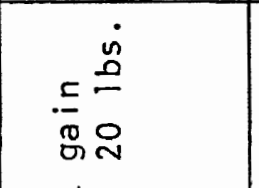 & & \\
\hline 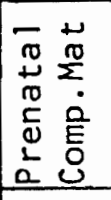 & 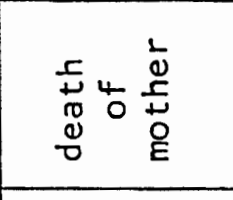 & $\therefore$ & 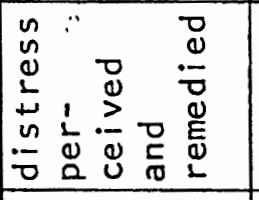 & & 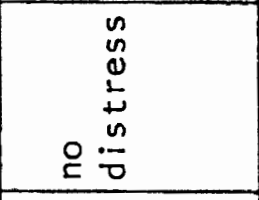 \\
\hline 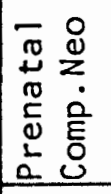 & 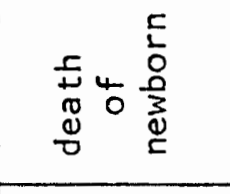 & & 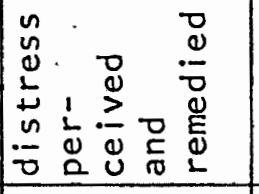 & & $\begin{array}{c}n \\
n \\
0 \\
1 \\
n \\
n \\
0 \\
0\end{array}$ \\
\hline 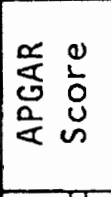 & 0 & & 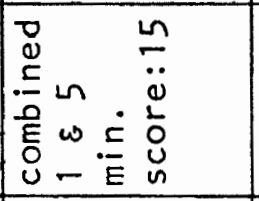 & & 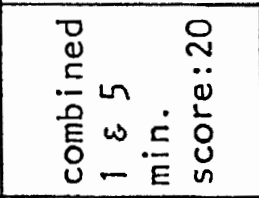 \\
\hline$\frac{5}{2} \frac{\frac{c}{0}}{\frac{0}{0}}$ & 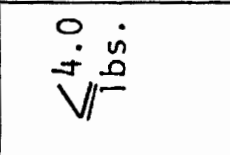 & & $\begin{array}{l}1 \\
0 \\
0\end{array}$ & & $\begin{array}{l}\dot{0} 0 \text { in } \\
\dot{n} \infty\end{array}$ \\
\hline \multirow[t]{2}{*}{$\frac{E}{\frac{1}{0}} \frac{1}{2}$} & 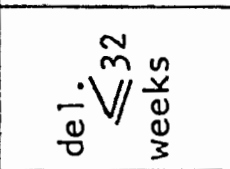 & & 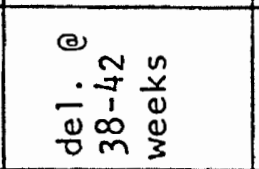 & & \\
\hline & 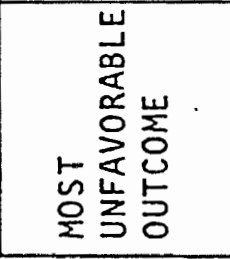 & 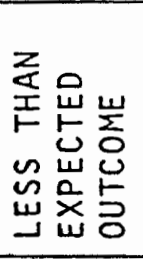 & 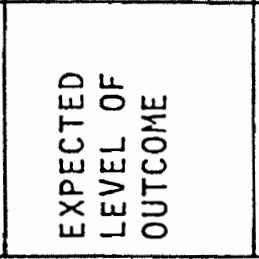 & 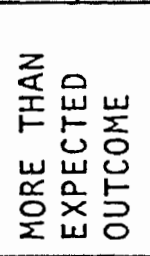 & 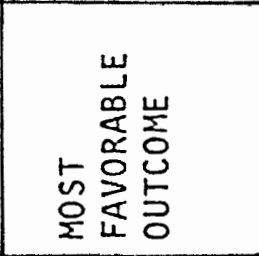 \\
\hline
\end{tabular}


This final case describes a woman requiring minimal medical and/or educational intervention.

Mrs. D. is married, age 26. Last menstrual period was 6 weeks ago. She is Gravida two, Para one, no abortions. First menstrual period age 13. She was seen last week. She suspects pregnancy. Complaints were nausea, and tiredness. She has one child, age 2, who was delivered at 41 weeks gestation without complications. Has had a positive urine screen for pregnancy. Ho history of complications with pregnancy. Has had all immunizations, PPD, and Pap smear. Pelvis is clinically adequate.

Initial Weight: 130 lbs. Height: 5 feet, 5 inches Blood pressure: $120 / 70$ HCT: 35.0

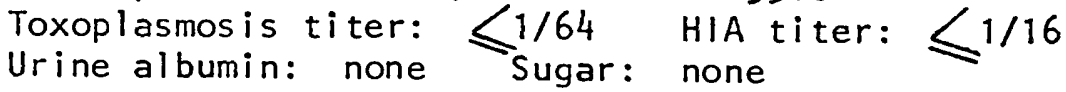
Mrs. D. describes herself as being happily married. Both her and her husband are looking forward to another child. She desires natural child birth as much as is possible. They will be attending classes. She desires to breast feed.

No medical or social problems are identified above. Outcome criteria are defined in Figure 5. The "expected levels of outcome," based upon her past medical history and present living situation, are defined within the normal range. The maintenance of her present psychological and socio-economic situation is expected. 


\begin{tabular}{|c|c|c|c|c|c|}
\hline 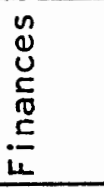 & 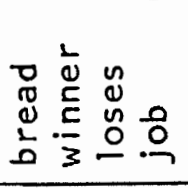 & & 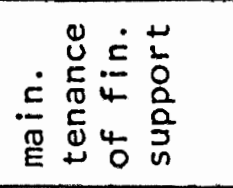 & & \\
\hline 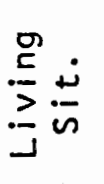 & 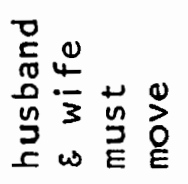 & & 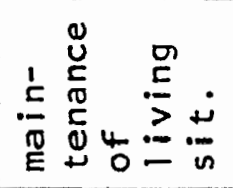 & & \\
\hline 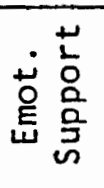 & 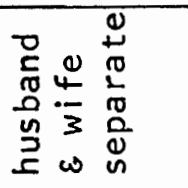 & & 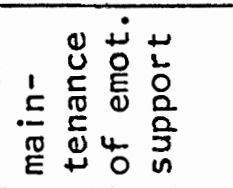 & $\because$ & \\
\hline $\begin{array}{l}-\pi \\
+\infty \\
0 \\
0 \\
0 \\
0 \\
1 \\
0 \\
0\end{array}$ & 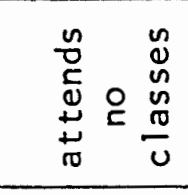 & & 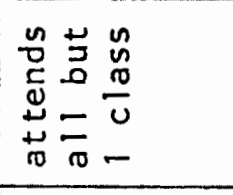 & & 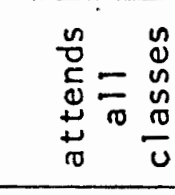 \\
\hline $\begin{array}{l}+\dot{0} \\
+\dot{0} \\
+\frac{1}{2}\end{array}$ & 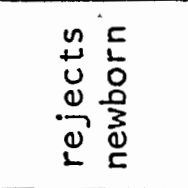 & & 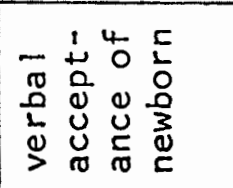 & & \\
\hline 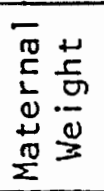 & $\frac{ \pm}{\tilde{c}}$ & & 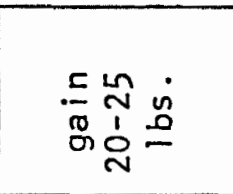 & & \\
\hline 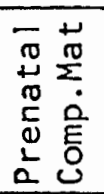 & 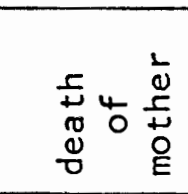 & 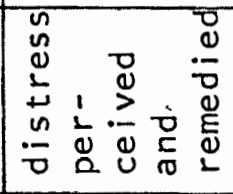 & $\begin{array}{c}n \\
n \\
0 \\
\frac{1}{2} \\
\frac{n}{n} \\
\frac{n}{0}\end{array}$ & & \\
\hline 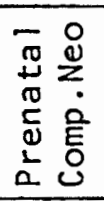 & \begin{tabular}{l}
5 \\
\multirow{2}{*}{} \\
0 \\
0 \\
0 \\
0
\end{tabular} & 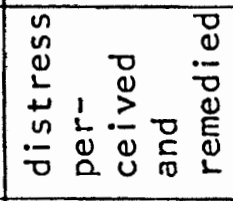 & 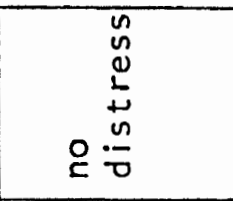 & & \\
\hline $\begin{array}{ll}\frac{0}{5} & 0 \\
5 & 0 \\
0 & u \\
\alpha & u\end{array}$ & 0 & & 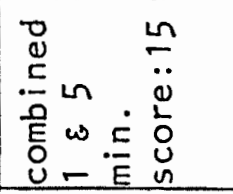 & & 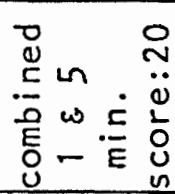 \\
\hline $\begin{array}{l}\frac{1}{ \pm} \\
\pm \frac{\pi}{\sigma} \\
\frac{1}{\infty}\end{array}$ & $\begin{array}{l}0 \\
\dot{n} \\
\dot{v}\end{array}$ & & $\begin{array}{l}1 \\
00 \\
0\end{array}$ & & $\begin{array}{l}1 \\
000 \\
000\end{array}$ \\
\hline \multirow[t]{2}{*}{ 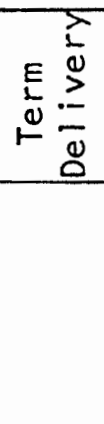 } & 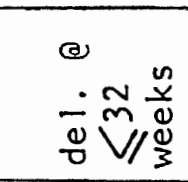 & & 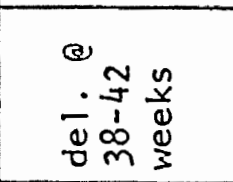 & & . \\
\hline & 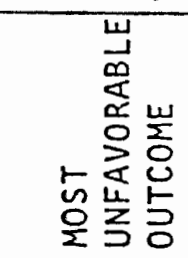 & 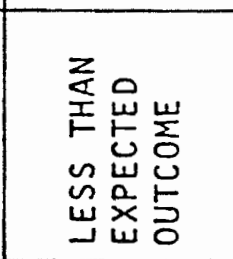 & 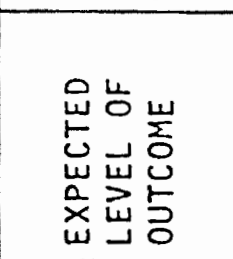 & 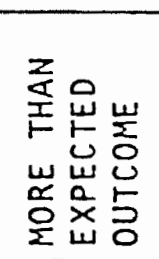 & 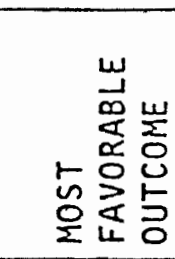 \\
\hline
\end{tabular}


CONCLUSION

Problems arise in level definition for one condition may be "most unfavorable" as the death of the newborn; however, if the infant was stillborn with severe congenital anomalies this may be seen as a "most favorable outcome."

The criteria shown on the three Goal Attainment Follow-up Guides are examples of how one may define the outcomes for each level. As more information is collected concerning an individual patient, it may appear more difficult to define what are the expected levels of success. The skill of prognosis then enters the picture. It is important to maintain the same specific criterion within all levels of one scale. One should also be careful to avoid the contingency of scales -- that all scale items are not dependent upon the result of one specific event (Garwick, 1975, p. 6).

Due to the lack of control over what may occur medically, resistance may arise on the part of the physician to commit him/herself to a specific criterion for evaluation. The goal of evaluation, however, is to discern what are the outcomes in relationship to what medical personnel desire and expect. This allows for the identification of those outcomes which are not meeting desired expectations so as to allow for further investigation into those areas. 


\section{CHAPTER V I}

\section{CONCLUSIONS AND RECOMMENDATIONS}

I believe that it is possible to utilize GAS in the measurement of the outcomes of medical care. At this point; however, there is the need for direct implementation to test the usefulness of the guidelines and to modify and adapt where needed. The need for direct involvement of medical personnel in the setting of scales and definition of criteria cannot be overstated. The criterion written for the medical scales of the three cases presented are limited by my own knowledge; however, they were utilized for the purpose of demonstration only.

GAS functions as a töol for the identification of specific program goals, individual patient goals, and the weaknesses within the delivery system. It can benefit the delivery of services (structure) as well as process and outcome. The Follow-up Guide provides a needed improvement in the chart system by way of bringing together the goals and needs of the patient on one page in the chart, facilitating better charting. The total care of the individual is defined, facilitating comprehensive management of care. Utilizing the health team approach, continuity of services is supported. The responsibility for outcome of care is spread throughout a variety of services -- physician, social worker, community resources and the patient.

If used as a tool of interaction and communication with each 
individual patient, patient understanding and compliance may be enhanced. At an individual level, one would be able to determine: Did the patient receive the care they wanted and/or needed?

The weaknesses of GAS lie in the flexibility of criterion setting. One health provider may set more stringent standards for a given goal than another, and thus would show less goal attainment. However, if coupled with a peer review, management and assessment of the criteria may be possible.

It is important to bear in mind that this is not a test of someone's competency (although it could be); but, a tool to be used to aid in providing better medical care to individual patients. 


\section{A SELECTED BIBLIOGRAPHY}

- Beaulieu, D. E. How to cope with staff resistance to program evaluation. Goal Attainment Scaling Workshop Compendium, $1973,84-90$.

Bracht, N. F. Health care the largest human service system. Social Work, September 1974, 532-541.

Brook, R. H., E Appel, F. A. Quality-of-care assessment: choosing a method for peer review. The New England Journal of Medicine, $1973,288,1323-1329$.

- Carlson, G. D. Communication skills training in a family practice residency program. Goal Attainment Review, 1974, 1, 55-68.

- Clarkson, Q. D., \& Koroloff, N., E Neuberger, W. F., \& Hines, S. Goal Attinament Scaling: A Review. Portland, Oregon: Regional Research Institute for Human Services, Portland State University, February 1976.

Clarkson, Q. D., \& Neuberger, W. F., E Koroloff, N. A System for Establishing Evaluation Standards. Portland, Oregon: Regional Research Institute for Human Services, Portland State University, E Beaverton Public Schools, March 1976.

- Davis, H. R. Four ways to Goal Attainment Scaling. Evaluation, 1973, 1, 43-48.

Donabedian, A. Evaluating the quality of medical care. Milbank Memorial Fund Quarterly, 1966, 44, 166-206.

Emanuel, 1. Problems of outcome of pregnancy: some clues from the epidemiological similarities and differences. In S. Kelly, E E. B. Hook, \& D. T. Janevick, \& 1. H. Porter (Eds.), Birth Defects: Risks and Consequences. New York: Academic Press, $1976,119-136$

Evaluating high-risk pregnancies. Briefs, February 1976, 25-26.

Ferster, G., E Jenkins, D. M. Patterns of antenatal care, perinatal mortality and birth weight in three consultant obstetric units. Lancet, 2 October 1976, 727-729.

Fessel, W. J., E Van Brunt, E. E. Assessing quality of care from the medical record. The New England Journal of Medicine, 1972, $286,134-138$. 
- Garwick, G. Guide construction guidelines: the follow-up date. P. E. P. News letter, January 1971, 4.

- Garwick, G. Guide construction guidelines: goal measurement. P. E. P. News letter, February 1971, 3.

- Garwick, G. What goes on a follow-up guide? P. E. P. Newsletter, April 1971, 2.

- Garwick, G. Guide construction guidelines: status at intake appear on the guide? October 1971,6 .

Should the patient's P. E. P. Newsletter,

October 1971,6 .

- Garwick, G. Goal Attainment Review 1. Minneapol is, Minnesota: Program Evaluation Resource Center, 1974.

- Garwick, G. Guidelines for Goal Attainment Scaling. Minneapol is, Minnesota: Program Evaluation Resource Center, 1975.

- Garwick, G., \& Lampman, S. Dictionary of Goal Attainment Scaling. Minneapolis, Minnesota: Program Evaluation Project, 1973.

Gonnella, J. S., \& Zeleznik, C. Factors involved in comprehensive patient care evaluation. Medical Care, 1974, 12, 928-934.

Gonnella, J. S., \& Louis, D. Z., \& McCord, J. J. The staging concept: an approach to the assessment of outcome of ambulatory care. Medical Care, 1976, 14, 13-21.

- Goal Oriented Record Keeping (G. O. R. K.). State of Oregon Mental Heal th Division, September 1975.

Greenwald, S. M. The relationship of Goal Attainment Scaling to psycho-dynamic constructs. Unpublished manuscript, Hennepin County Mental Health Center, Minneapolis, Minnesota.

Honigfeid, G., E Klein, D. F. The Hillsdale Hospital patient progress record: explorations in clinical management by objective and exception. Evaluation, 1973, 1, 19-22.

- Houts, P. S., \& Scott, R. A. Behavioral objectives and Goal Attainment Scaling: unstrange bedfellows. Unpublished manuscript, Department of Behavioral Science, Pennsylvania State University, The Milton S. Hershey Medical Center, Hershey, Pennsylvania.

Kessner, D. M., \& Kalk, C. E., \& Singer, J. Assessing health quality: the case for tracers. The New England Journal of Medicine, $1973,288,189-194$.

Kessner, D. M. Quality assessment and assurance: early signs of cognitive dissonance. Seminars in Medicine of the Beth Israel Hospital, Boston, $1978,298,381-386$. 
- Kilber, S., E Swanson, C. The application and evaluation of Goal Attainment Scaling to the JANIS drug treatment program. Unpublished Master's Thesis, Portland State University, Portland, Oregon, 1975.

- Kiresuk, T. J., E Sherman, R. E. Goal Attainment Scaling: a general method for evaluating comprehensive mental health programs. Community Mental Health Journal, 1968, 4, 443-453.

- Kiresuk, T. J. The future of Goal Attainment Scaling. Goal Attainment Scaling Workshop Compendium, 1973, 101-104.

Lane, D. S., E Kellman, H.R. Assessment of maternal health care quality: conceptual and methodological issues. Medical Care, $1975,13,791-807$.

Lawson, J. G. Avoidable factors in maternal deaths. Nursing Mirror, 12 September 1974, 48-50.

Lebow, J. L. Consumer assessment of the quality of medical care. Medical Care, $1974,12,328-337$.

Linn, M. W., E Linn, B. S. Narrowing the gap between medical and mental health evaluation. Medical Care, 1975, 13, 607-614.

Lorei, T. W., E Schroeder, N. H. Integrating program evaluation and medical audit. Hospital and Community Psychiatry, 1975, 26, 733-735.

Nunally, D. M., E Aguiar, M. B. Patient's evaluation of their prenatal and delivery care. Nursing Research, 1974, 23, 469-474.

Prenatal care and pregnancy outcome. Briefs, May 1976, 67-69.

- Programmed Instruction in Goal Attainment Scaling. Minneapolis, Minnesota: Program Evaluation Resource Center, 1974.

Ryan, G. M., Jr. Toward improving the outcome of pregnancy: recommendations for the regional development of perinatal health services. Journal of Obstetrics and Gynecology, $1975,46,375-384$.

Sanazaro, P. J., E Goldstein, R. L., E Roberts, J. S., E Maglott, D. B., $\varepsilon$ McAllister, J. W. Research and development in quality assurance: the experimental medical care review organization program. The New England Journal of Medicine, 1972, 287, $1125-1131$.

Social pathology and maternal care. Briefs, February 1969, 19-23.

Stedman's Medical Dictionary. 22nd Edition. Baltimore, Maryland: The Williams \& Wilkins Company, 1972, 1129. 
- Turner, J. A. Evaluating a community mental health center. Goal Attainment Scaling Workshop Compendium, 1973, 23-26.

Watt, J. E. Two aspects of program evaluation. Unpublished manuscript, Jackson Memorial Hospital, Outpatient Department, Psychiatry, Miami, Florida.

White, K. Evaluation of medical evaluation and health care. In W. Latham, \& A. Newberry, (Eds.), Community Medicine: Teaching, Research and Health Care. New York: AppletonCentury-Crofts Educational Division/Meredith Corp., 1970, 241-270.

Williamson, J. W. Evaluating quality of patient care: a strategy relating outcome and process assessment. JAMA, 1971, 218, 564-569.

-Wilson, N. C., \& Mumpower, J. L. Automated evaluation of goal attainment ratings. Hospital and Community Psychiatry, 1975, 26, $163-164$. 


\section{APPENDIX}

DATA SHEET

UNIT NO.

AGE

$15-20=$
$21-30=$
$31-35=$
$>35$

MARITAL STATUS: single married separated divorced widowed other

GESTATIONAL AGE: by date given GRAVI DA

$$
\text { clinically }
$$

PARA

ABORTIONS

PPD: yes IMMUNIZATIONS:

yes

PAP SMEAR: yes

no

no no

PELVIS clinically adequate: $A-P \times B i S p i n o u s=>120 \mathrm{~cm}^{2}$ inadequate: $A-P \times B$ iSpinous $=<120 \mathrm{~cm}^{2}$ INITIAL BP DIASTOLIC: $<90$ LAST BP@ DELIVERY:

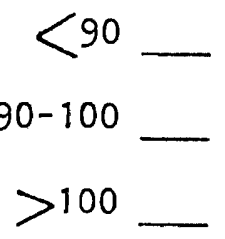

INITIAL WT.

LAST WT. @ DELIVERY

IDEAL WT. + 26

EXCESS WT.

$<10$

$11-30$

$31-50$

$>51$ 
BLOOD TYPE

RH TYPE

TOXOPLASMOSIS TITER:

HIA TITER:

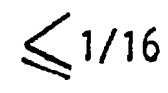

URINE ALBUMIN: yes

SUGAR: yes

$$
\leqslant 1 / 64 \ldots>1 / 64
$$

LAST HCT @ DELIVERY

INITIAL HCT

no

no

NO. OF VISITS ANTEPARTUM: 0-5

$$
\begin{array}{r}
6-10 \\
11-15 \\
>15
\end{array}
$$

LABOR \& DELIVERY:

BP ever $>100 \mathrm{~mm}$ diastolic yes

no

LOCAL ANESTHESIA: yes

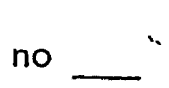

FETAL - variable deceleration: yes

ANALGESIC: yes

no

\section{late deceleration: yes}

OUTCOME: vaginal

$$
\text { c-section }
$$

INFANT APGAR: $1 \mathrm{~min} .0-5$

5 min. $0-5$

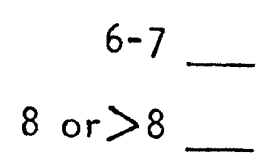

INFANT WT. $<5.5$

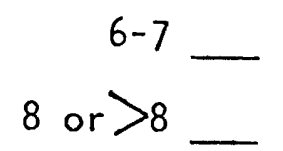

$$
\begin{array}{r}
5.6-7.0 \\
7.1-8.5 \\
>8.5
\end{array}
$$

DISCHARGE HCT ON MOTHER: >30\% 
WANTED CHILD: yes

PREVIOUS MARRIAGES: yeS

no

no

QUALITY MARITAL RELATIONSHIP:

ATTITUDE TOWARD CHILD REARING:

EXPERIENCES WITH OWN PARENT:

POST PARTUM DEPRESSION, HISTORY: 